\title{
Swipe and Wipe
}

\section{Dear Reader,}

It is not true that the past was a golden age. My first car, an Opel Kadett C, had no headrests on the front seats, no safety belts for the passengers in the rear, no airbags and no ABS. However, it was easy to operate the turn signals, the ignition switch, the radio and the windshield wipers, for example, because the controls were all in familiar places. But those days are long gone. The turn signal switch is the only one of these that is still in the same location in most current car models. More and more controls are now electronic rather than mechanical and this is not always a positive development, as one Tesla driver discovered.

Using an electronic device of the kind that almost everyone owns nowadays while driving can prove to be an expensive mistake. In Germany, if you use your smartphone at the wheel you will incur a fine of at least 100 euros and a penalty point on your driving license. The definition of the word "use" has been the subject of years of disputes and sometimes contradictory court judgments. But now we all know that once the engine is running we must keep our hands away from our phones, because they can't be used even if they are in a bracket and even for the purposes of navigation. Section 23 of the German Road Traffic Regulations states: "Anyone who drives a vehicle may use an electronic device designed for communication, information or organization [...] only if they can use the device simply [...] by looking briefly [...] at it.”

And now we are back to the Tesla driver. He was using an "electronic device" while driving last year, was distracted by it, left the road and crashed into a tree. The unusual feature of this accident is that the device in question was factoryfitted. In this electric car, you have to set the wiper interval by swiping a touch screen to access a submenu. The judges at the higher regional court in Karlsruhe (Germany) ruled that this constituted an illegal distraction and imposed a 200euro fine and a month-long driving ban on the driver.

This dramatic decision must have led to unusual levels of activity in many of the departments responsible for developing HMI systems at car companies and automotive suppliers. It may be that innovative products which have already been completed are now being radically changed or even discontinued altogether. What does this ruling really mean? It means simply that manufacturers may be selling cars which will inevitably result in drivers breaking the law because of the way they are designed. It turns out that some things were actually better in the old days - the windshield wiper switch for example.

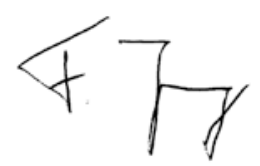

Frank Jung

Editor

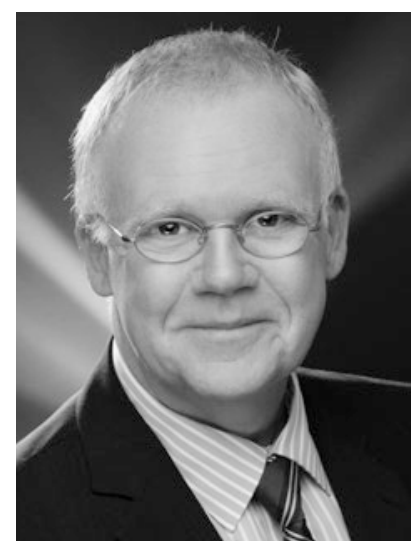

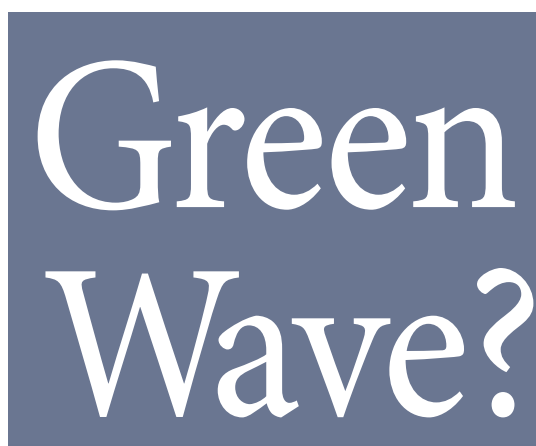

It's all down to R\&D.

The future of driving is electric. But short ranges and long charging times are holding back that future. With our energy-efficient battery management systems, green means go. And with those greener drivetrains, we want to inspire people to embrace cleaner mobility. Count on our experts to develop the operating, power supply, charging and predictive range management strategies that put you in the express lane. Delivering technologies that move people is what we do.

ITK Engineering GmbH - Go green with our system and software solutions.

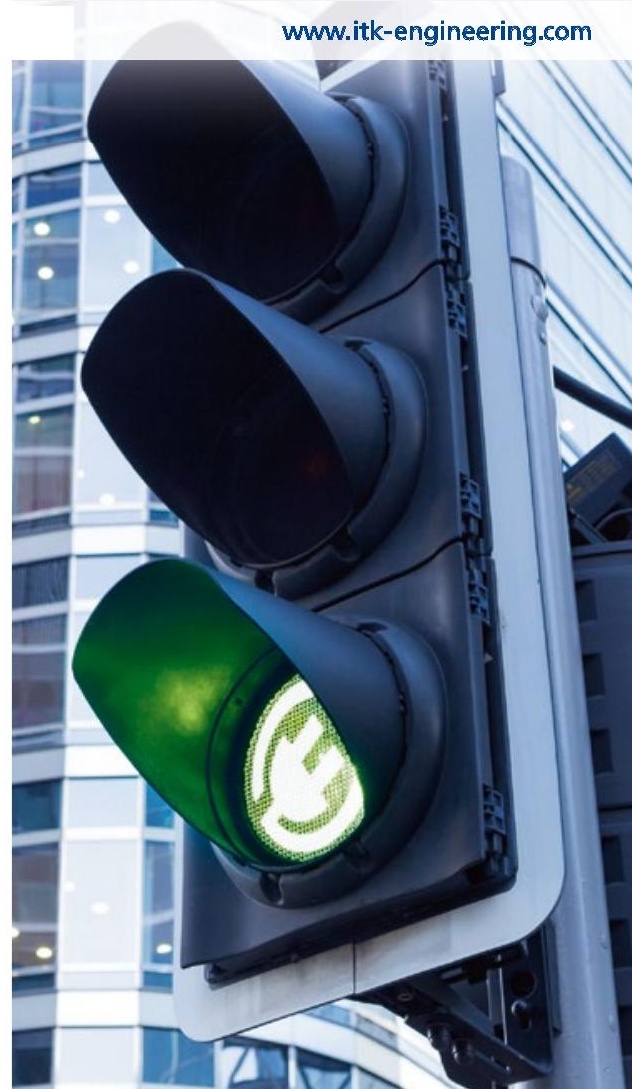

